\title{
INQUÉRITO POPULACIONAL SOBRE O COMPORTAMENTO SUICIDA NO MUNICÍPIO DE PIANCÓ (PB)
}

\author{
POPULATION SURVEY ABOUT SUICIDE BEHAVIOR IN THE CITY \\ OF PIANCÓ(PB)
}

\author{
Débora Priscila Ferreira da Silva Gomes ${ }^{1}$ \\ Emilene Nóbrega Medeiros ${ }^{2}$ \\ Josilene Nascimento Rodrigues ${ }^{3}$
}

\begin{abstract}
RESUMO: O suicídio é um complexo fenômeno que demanda debates, estudos e ações estratégicas governamentais. Objetivo: Verificar a ocorrência do comportamento suicida na população de Piancó - PB. Método: Estudo transversal, descritivo e exploratório, de cunho quantiqualitativo. Os dados foram coletados mediante aplicação de questionário sociodemográfico e roteiro de entrevista estruturada. Os participantes foram abordados em seus espaços de convívio cotidiano, bem como em salas de espera de Unidades Básicas de Saúde. Resultados: A análise das ocorrências do comportamento suicida e o cruzamento de variáveis mostrou a prevalência do fenômeno em participantes com o seguinte perfil: sexo feminino; estado civil casado; religião católica; nenhum ou poucos anos de escolaridade, desempregado, natural do município em questão; com filhos. O estudo dos aspectos psicossociais revelou o aumento do risco entre as pessoas com padrão de uso habitual de substâncias psicoativas, que passaram pelo luto por suicídio, vivenciam com frequência sentimentos de desespero, desamparo, desesperança e depressão e membros de famílias que se caracterizam pela fragilidade dos vínculos afetivos. Eventos tais como mortes de pessoas importantes, conflitos familiares e separações foram amplamente mencionados e em alguma
\end{abstract}

\footnotetext{
${ }^{1}$ Graduada em Psicologia pela Universidade Estadual da Paraíba. Especialista em Saúde Coletiva pelo Centro Universitário de Patos. Possui curso de aperfeiçoamento em Impactos da Violência na Saúde pela Fundação Oswaldo Cruz. Mestranda em Psicologia da Saúde pela Universidade Estadual da Paraíba. Endereço eletrônico: debora_priscila@hotmail.com.

${ }^{2}$ Graduada em Psicologia pelo Centro Universitário de João Pessoa - UNIPÊ. Especialista em Saúde Coletiva - NESC/CCS/UFPB, Especialista em Envelhecimento em Saúde - PPGENF/UFPB, Mestre em Enfermagem e Saúde Pública - PPGENF/UFPB. Doutoranda em Enfermagem pela Universidade Federal da Paraíba. Profissional de Saúde da Caixa de Assistência dos Funcionários do Banco do Brasil - CliniCASSı João Pessoa/Pb. E-mail: emilenenobrega@gmail.com.

3 Graduada em Psicologia pela Universidade Federal da Campina Grande, Especialista na modalidade de Residência Multiprofissional em Saúde da Família e Comunidade da Faculdade de Ciências Médicas da Paraíba, Mestranda em Psicologia da Saúde pela Universidade Estadual da Paraíba. Endereço eletrônico: lene-nr@hotmail.com.
} 
medida associados ao comportamento suicida. Conclusão: Prevaleceu entre os entrevistados a visão do suicídio como ato desviante, resultado de tentação do mal e justificado pela falta de Deus. Essa compreensão, pelo seu caráter, estigmatizante dificulta a busca de apoio profissional em situações de maior vulnerabilidade. É ressaltada a necessidade de novos estudos para ampliar a compreensão do fenômeno do suicídio no município.

Palavras chave: Suicídio. Tentativa de Suicídio. Ideação Suicida. Comportamento Autodestrutivo.

ABSTRACT: Suicide is a complex phenomenon that requires debates, studies and strategic government actions. Objective: Verify the occurrence of suicidal behavior in the population of Piancó - PB. Method: Cross-sectional, descriptive and exploratory study, of quantitative and qualitative nature. Data were collected through the application of a sociodemographic questionnaire and a structured interview script. The participants were approached in theirdaily living spaces, as well as in waiting rooms in Basic Health Units. Results: The analysis of the occurrences of suicidal behavior and the crossing of variables showed the prevalence of the phenomenon in participants with the following profile: female; married marital status; Catholic religion; none or a few years of schooling, unemployed, born in the municipality in question; with children. The study of psychosocial aspects revealed an increased risk among people with a pattern of habitual use of psychoactive substances, who went through grief by suicide, often experience feelings of despair, helplessness, hopelessness and depression and family members who are characterized by fragility of affective bonds. Events such as deaths of important people, family conflicts and separations have been widely mentioned and tosome extent associated with suicidal behavior. Conclusion: Among the interviewees, the view of suicide asa deviant act prevailed, the result of temptation to evil and justified by the lack of God. This understanding due to its stigmatizing character makes it difficult to seek professional support in situations of greater vulnerability. The need for further studies is emphasized to broaden the understanding of the suicide phenomenon in the municipality.

Keywords: Suicide. Suicide, Attempted. Suicidal Ideation. Self-Injurious Behavior 


\section{INTRODUÇÃO}

A palavra suicídio tem origem no latim, derivada da junção das palavras sui (simesmo) e caederes (ação de matar). A expressão sui caedere, portanto, significa cair ou morrer pela própria mão (GONÇALVES, 2018).

Conforme a definição da Organização Mundial de Saúde (OMS), o termo suicídio corresponde ao "ato deliberado, intencional, de causar a morte a si mesmo, ou em outras palavras, um ato iniciado e executado deliberadamente por uma pessoa que tem a clara noção (ou uma forte expectativa) de que dele pode resultar a morte, e cujo desfecho fatal é esperado" (OMS, 1998 apud BERTOLOTE, 2012, p.21).

O suicídio é um problema de saúde pública de nível global e a sua ocorrência está relacionada a múltiplas causas, afetando pessoas de todas as classes socioeconômicas, religiões e credos, gêneros, raças, etnias e faixas etárias. Estimase que em todo o mundo as mortes autoprovocadas correspondem a mais de 800 mil óbitos, sendo ainda mais elevados os números das tentativas de suicídio (MS, 2017; OMS, 2014).

O comportamento suicida envolve condutas de risco que tem inicio com os pensamentos acerca da possibilidade de autodestruição, que diz respeito à ideação suicida. Outra etapa possível, nesse contexto, e que sinaliza para um nível de gravidade crescente, diz respeito à elaboração de um plano de suicídio. A tentativa de autodestruição, por sua vez, expressa a intensidade do sofrimento psíquico e severidade da intenção e de dar cabo da própria vida, e pode resultar no suicídio consumado (ABP, 2014; OMS, 2014).

Determinadas circunstâncias problemáticas e desafiadoras da existência humana podem suscitar pensamentos passageiros sobre matar-se enquanto saída para o sofrimento vivenciado naquele momento pontual. (CASSORLA, 2017). Entretanto, é necessário examinar cuidadosamente o contexto em ocorrem essas 
ideias, tal como a sua durabilidade e constância, visto que pode evoluir para um plano elaborado ou mesmo uma tentativa de suicídio (TRIGUEIRO, 2017).

A ocorrência de pensamentos de cunho autodestrutivo associa-se a um risco considerável de tentativa de suicídio e, por conseguinte, um aumento do risco de suicídio. "A presença de ideação suicida é, por si só, um importante sinal de sofrimento psíquico e exige atenção redobrada na avaliação clínica. Um transtorno psiquiátrico pode estar presente, necessitando de reconhecimento e de tratamento adequado" (BOTEGA, 2015, p.99).

As tentativas de autodestruição não ocasionam o suicídio consumado, de maneira indubitável, entretanto constituem principal fator de risco para o suicídio. As pessoas que empreenderam tentativas de suicídio pertencem a um grupo de significativa vulnerabilidade, pois poderão realizar novas tentativas no futuro, mediante a persistência do quadro vivencial gerador de sofrimento e desespero (OMS, 2000).

Os fatores que propiciam o comportamento suicida são complexos e multidimensionais. Estes vão desde elementos de vivências sociofamiliares negativas, passando por condições individuais de saúde ou doença psicológica e física, perdas, separações, histórico de suicídio na família, tentativas anteriores e acesso aos meios letais (OMS, 2000).

Assim sendo, o suicídio não pode ser considerado manifestação de problema meramente individual. Questões sociais e econômicas; condições dignas de existência; qualidade de vida e saúde; fatores culturais, religiosos e familiares; e, acesso às politicas públicas são aspectos que precisam ser observados, especialmente por sua vinculação com a saúde mental da população. A problemática que envolve o suicídio, portanto, extrapola a esfera pessoal (MINOIS, 2018; BOTEGA, 2015; OMS, 2004).

O crescimento das taxas de suicídio deve impulsionar estudos junto às populações mais vulneráveis ao fenômeno, com vistas à compreensão de fatores de risco diversos que contribuem para a elevação do número de mortes. A necessidade dessa investigação se impôs a partir da frequente observação de óbitos por suicídios, ao longo dos anos, notadamente a partir de 2013, em Piancó, município situado na mesorregião do Sertão Paraibano. 
Os números coletados no Sistema de Informações sobre Mortalidade - SIM do Departamento de Informática do Sistema Único de Saúde - DATASUS referentes aos óbitos por lesões autoprovocadas ocorridos em 2018 apontam que a taxa de mortalidade por suicídio em Piancó-PB no período foi equivalente a 31/100.000 habitantes. O coeficiente encontrado no município superou até mesmo as taxas para o mesmo período em âmbito nacional, regionale estadual, que foram de 6,1/ 100.000 habitantes, 5,2/ 100.000 habitantes e 5,9/ 100.000 habitantes, respectivamente. Outra importante questão acerca do índice verificado é que segundo a classificação da OMS a taxa de suicídios encontrada no município é considerada muito alta (acima de 30/100.000 habitantes) (CRUZ, 2012).

Tais fatos apontam a necessidade de conhecer melhor a realidade psicossocial apontada pelas informações oficiais de saúde, buscando o reconhecimento de fatores diversos de implicados no aumento das ocorrências. No intento de ampliar a compreensão do comportamento suicida de acordo com os que o vivenciam e, destarte, promover reflexões que contribuem para sua prevenção é que esse estudo foi aplicado.

\section{MÉTODO}

Estudo transversal, descritivo e exploratório, com abordagem quantiqualitativa, realizado junto à população do munícipio de Piancó, estado da Paraíba. A amostra foi composta por 51 participantes, acima de 18 anos de idade, residentes no munícipio supracitado. Na coleta de dados foram utilizados: Questionário sociodemográfico para conhecer o perfil dos participantes e roteiro de entrevista estruturado com questões acerca do comportamento suicida e aspectos psicossociais.

A investigação iniciou com abordagem aleatória dos participantes em seus espaços de convívio cotidiano; logradouros, residências, praças públicas, bem como em salas de espera das Unidades Básicas de Saúde localizadas na zona urbana, após a assinatura do Termo de Consentimento Livre e Esclarecido - TCLE. O estudo 
respeitou todas as etapas relativas aos procedimentos éticos em pesquisas que envolvem seres humanos, tendo iniciado após aaprovação pelo Comitê de Ética em Pesquisa das Faculdades Integradas de Patos - FIP.

Os dados do questionário sociodemográfico foram processados através do Software Statistical Package for the Social Sciences-SPSS, que realizou cálculos de média, frequênciae proporção, conferindo a relação entre variáveis diversas acerca do perfil dos participantes. Os resultados da entrevista estruturada visando conhecer vivências e percepção acerca do comportamento suicida foram analisados por meio da Análise de Conteúdo do tipo categorialtemática.

\section{RESULTADOS E DISCUSSÃO}

Os 51 participantes do estudo residem em dezesseis diferentes localidades (bairros e conjuntos) do município: Alto Belo-Horizonte; Piancozinho; Mutião; Conjunto Felizardo Leite; Praça do Cossaco; Ouro Branco; Campo Novo; Santo Antônio; Conjunto Mariz; Rua Velha; Conjunto Socorro Brasilino; Rua Velha; Sítio Pitombeira; Rua da Cadeia; São Vicente; Caixa d'Água; Avenida Gil Galdino. Em $56,9 \%$ dos casos, a naturalidade dos entrevistados é piancoense. A média das idades é de 48 anos, sendo a mínima de 18 anos e a máxima de 82 anos. A média de moradores na casa é equivalente a 3,5, sendo mínimo de 01 morador e o máximo de 09 moradores.

As respostas às questões acerca do comportamento suicida revelaram que: $37,3 \%$ dos participantes relataram ter desenvolvido ideação suicida, $25,5 \%$ iniciaram a elaboração de um plano de suicídio; e $27,5 \%$ chegaram a efetuar uma ou mais tentativas de autoextermínio. Entre os entrevistados, 47,1\% dizem conhecer alguma pessoa (familiar, amigo, conhecido) que consumou o suicídio; e 54,9\% afirmaram vivenciar com frequência algum dos sentimentos dos 4Ds (depressão, desesperança, desamparo e desespero). 
Figura 1: Ocorrência do comportamento suicida na população estudada.

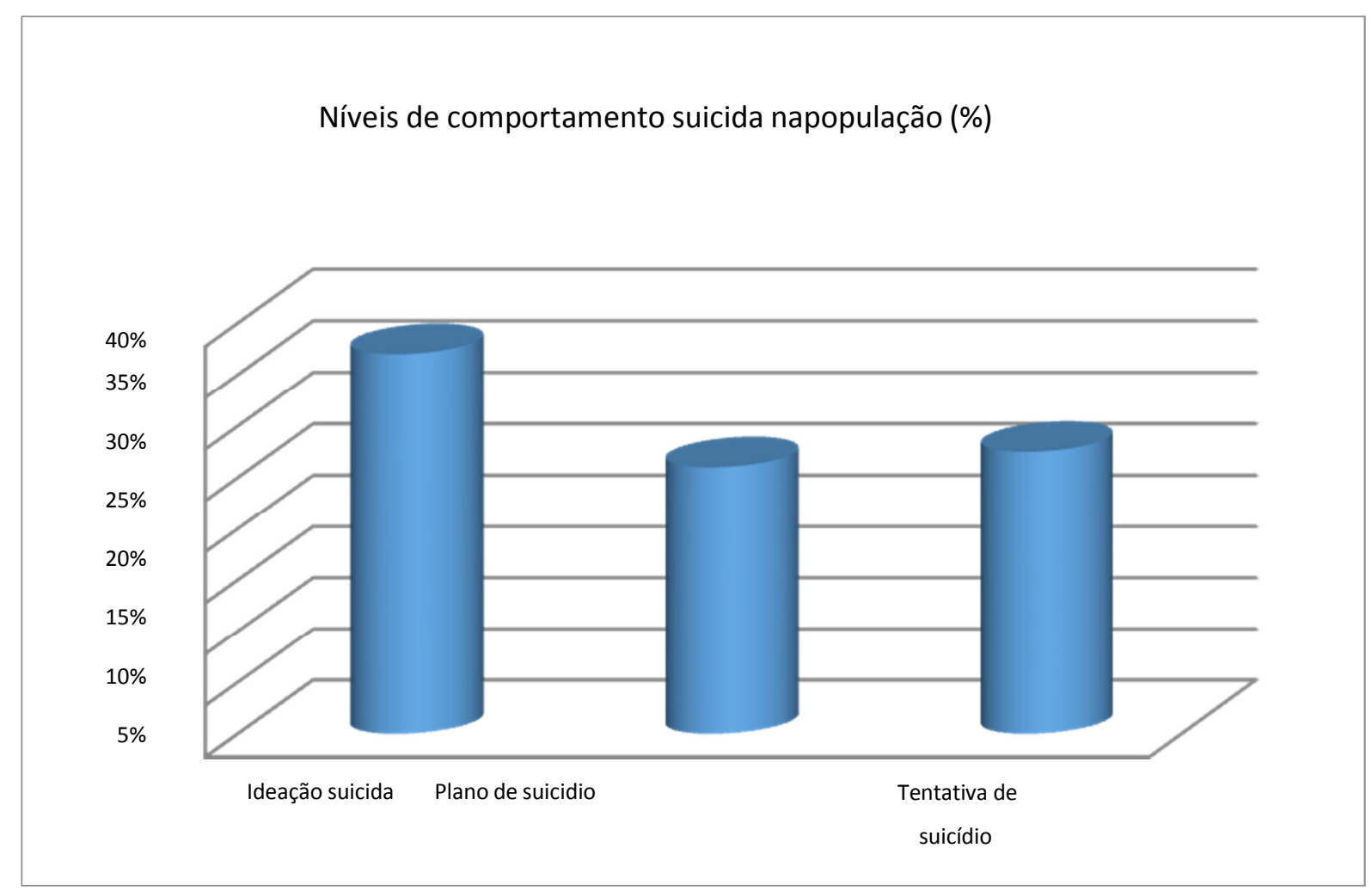

Resultados sobre a ocorrência do comportamento autodestrutivo foram classificados conforme as Unidades Básicas de Saúde - UBS, que atendem aos diferentes locais de residência. No território de abrangência da UBS Teotônio Neto, tanto a ideação suicida como o relato de tentativas de suicídio incidiram em $33 \%$ dos participantes, representando as frequências mais elevadas por unidade de saúde. O planejamento da própria morte ocorreu de modo mais acentuado (30\%) nas pessoas assistidas pela UBS Paulo Montenegro. A menor frequência de ideação suicida $(25 \%)$ foi percebida na população pertencente à UBS Eudo Moura Diniz, enquanto o planejamento e ocorrência de tentativas de suicídio foram menos frequentes (24\%) nos usuários da UBS Fernando Vieira de Melo. Conforme pode ser observado na figura abaixo. 
Figura 2: Frequência dos níveis de comportamento suicida nas Unidades Básicas de Saúde.

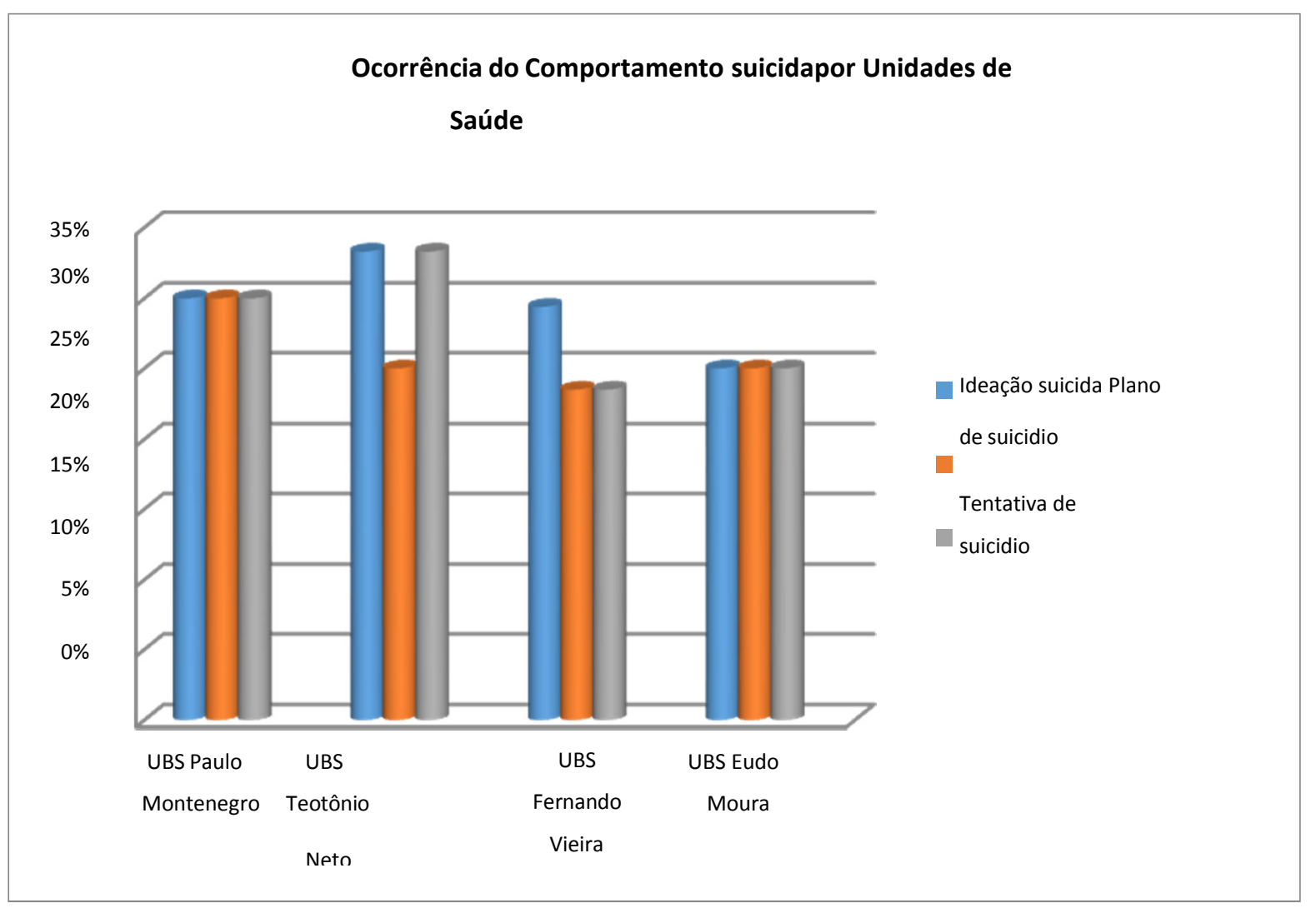

Junto aos participantes que desenvolveram ideação suicida, e de acordo com o perfil sociodemográfico, foi observado que: $68,4 \%$ eram do sexo feminino; $57,9 \%$ estavam casados; $47,4 \%$ eram católicos, $68,5 \%$ não estudaram ou estudaram até o fundamental I; 42,1\% estavam desempregados; 57,9\% nasceram no munícipio do estudo; $84,2 \%$ possuem filhos.

Quanto aos que desenvolveram plano de suicídio: 69,2\% eram do sexo feminino; $53,9 \%$ estavam solteiros ou separados; $76,9 \%$ possuíam alguma religião, $69,3 \%$ não estudaram ou estudaram até o fundamental I; 46,2\% estavam desempregados; $69,2 \%$ nasceram no munícipio do estudo; $84,6 \%$ possuem filhos.

No grupo que efetuou uma ou mais tentativas de suicídio: $57,1 \%$ eram do sexo feminino; $50 \%$ estavam casados; $42,9 \%$ eram católicos, $85,7 \%$ não estudaram ou estudaram até o fundamental I; $35,7 \%$ estavam desempregados; $64,3 \%$ nasceram no munícipio do estudo; $85,7 \%$ possuem filhos. 
Foi significativa a relação encontrada entre o consumo frequente de substâncias psicoativas (álcool, tabaco e ansiolíticos) e o fenômeno em tela. O uso de substâncias esteve presente em 68,4\% dos participantes que declararam a ocorrência de pensamentos suicidas, $84,6 \%$ dos que chegaram a desenvolver algum plano de suicídio, e 71,4\% dos que realizaram tentativas de suicídio.

Um relevante aspecto psicossocial diz respeito ao participante que sofreu a perda de familiar, amigo ou conhecido para a morte por suicídio. O lugar de sobrevivente enlutado foi vivenciado por $57,9 \%$ dos que desenvolveram ideação suicida e $57,1 \%$ dos que apresentaram histórico de tentativa de suicídio.

Outro fator que apresentou correlação importante com o comportamento suicida foi o relato da vivência frequente de sentimentos de desespero, desamparo, desesperança e depressão (4D), esses estiveram presentes em 84,2\% daqueles com perfil para ideação suicida, $76,9 \%$ dos que planejaram e $71,4 \%$ do que fizeram tentativas.

O suporte familiar e a qualidade dos vínculos familiares foi uma das variáveis da dimensão psicossocial analisadas no estudo. Nesse contexto, foi identificado que entre os participantes que classificaram suas relações familiares como muito ruins, $80 \%$ revelaram comportamento suicida em todos os níveis de risco para o suicídio (ideação, planejamento e tentativa).

A análise das ocorrências do comportamento suicida e o cruzamento de variáveis sociodemográficas mostrou a prevalência do fenômeno no grupo constituído por participantes com o seguinte perfil: sexo feminino; estado civil casado; religião católica; nenhum ou poucos anos de escolaridade, desempregado, natural do município em questão; com filhos.

O estudo dos aspectos psicossociais, por sua vez, revelou o aumento do risco de comportamento suicida entre as pessoas com padrão de uso habitual de substâncias psicoativas, que passaram pelo luto por suicídio, vivenciam com frequência sentimentos de desespero, desamparo, desesperança e depressão e membros de famílias que se caracterizam pela fragilidade dos vínculos e suporte afetivo. 
Eventos vitais, sofrimento psíquico e comportamento suicida

Acontecimentos inesperados e singulares da vida podem desencadear crises circunstanciais e, a depender dos recursos pessoais para lidar com a complexidade da situaçãoe do modo como Ihes são atribuídos os significados, tais eventos podem levar ao colapso existencial. Vivências decorrentes desse quadro (angústia, incapacidade, desespero, etc.) aumentam a vulnerabilidade para o suicídio, que passa a ser encarado como solução (BOTEGA, 2015).

O conteúdo das entrevistas permitiu identificar situações geradoras de sofrimentoemocional na trajetória de vida do grupo que apresentou risco para o suicídio. A maior frequência de problemas mencionados esteve relacionada ao falecimento de familiares (mãe, pai, filho, irmão, tio, primo). É notória a dor e o sofrimento causados, além do impacto das perdas afetivas nas seguintes falas: "Perdi minha filha mais velha, mataram. Foi a maior perdaque eu tive na vida. Ela tinha 19 anos" (P.14); "Já, né? Porque a pessoa perder pai e mãe não éa mesma coisa" (P.17). "Quando tinha 19 anos, perdi minha mãe e o filho em seguida. Fiquei sofrendo. Irmão não é que nem mãe, né? Tive que enfrentar a vida" (P.38).

Outra dificuldade largamente mencionada diz respeito à vivência de conflitos e violência no âmbito do convívio familiar e relacional (pais e cônjuges). "Fui abandonada, criada sem pai nem mãe" (P.29); "... Relacionamento possessivo e conflitos familiares" (P.34); "... era maltratada quando vivia com o outro marido" (P.45).

O processo de adoecimento traz implicações importantes na vida das pessoas. Um dos participantes ao afirmar que foi difícil enfrentar "a trombose", evidenciou como tal situação representou grande mudança em sua forma de encarar a vida: "Antes disso era o homem mais feliz do mundo" (P.27). Ademais, separações conjugais, eventos traumáticos (acidente de trânsito, prisão do cônjuge) e dificuldades financeiras foram outras problemáticas relatadas pelo grupo com vivência de comportamento suicida (ideação, plano, história de tentativa). 
Botega (2015), ao assinalar a existência de fatores de riscos, faz a diferenciação entre fatores predisponentes e precipitantes, esses últimos dizem respeito a eventos dolorosos e recentes que geram sofrimento psíquico agudo e podem desencadear o comportamento suicida. Os fatores distais são menos perceptíveis, mas contribuem para o surgimento da crise, a exemplo dos transtornos psiquiátricos, abuso sexual na infância, doenças incapacitantes e história de suicídio na família, para citar alguns.

\section{Compreensões sobre o Suicídio}

A análise das percepções e atitudes sobre $\mathrm{O}$ ato suicida mostrou a predominância do significado espiritual dado ao fenômeno pelos participantes da pesquisa. Foi significativa a quantidade de vezes em que o suicídio foi associado a um ato desviante, pecaminoso e, portanto, condenável. Tal atitude de julgamento está contida nas assertivas a seguir: "Eu acho assim: quem morre por suas mãos vai pra o escuro." (P.3); "A pessoa que se mata não pra o céu, né?" (P.10); "A pessoa que se mata é pecado." (P.31); "Eu acho que é errado, porque Deus não permite que ninguém se mate com as próprias mãos." (P.50).

A falta de Deus, revelada pela ausência de fé, oração e amor ao criador, é a explicação dada por alguns participantes, segundo alguns dos quais: "Acho que é uma pessoa... que não tem fé em Deus." (P.23); “... e pouca oração” (P. 20); “Eu já pensei, mas no mesmo momento que toca em mim é Deus" (P.32); "Falta de amor a Deus (P.33)".

Numa perspectiva semelhante, o significado atribuído ao comportamento suicida por alguns entrevistados é de que o mesmo é decorrente de tentação espiritual, o comportamento autodestrutivo seria o resultado de um combate em que forças do mal vencem o bem. Os fragmentos a seguir revelam tal entendimento: "O diabo fala mais alto do que Deus." (P.18); "É tentação do demônio." (P.21); "Acho que é tentação do sujo." (P.27); "Eu acho que seja uma pessoa muito tentada" (P.44). 
Figura 3: Nuvem de palavras repetidas com maior frequência.

Fonte: Wordclouds.com

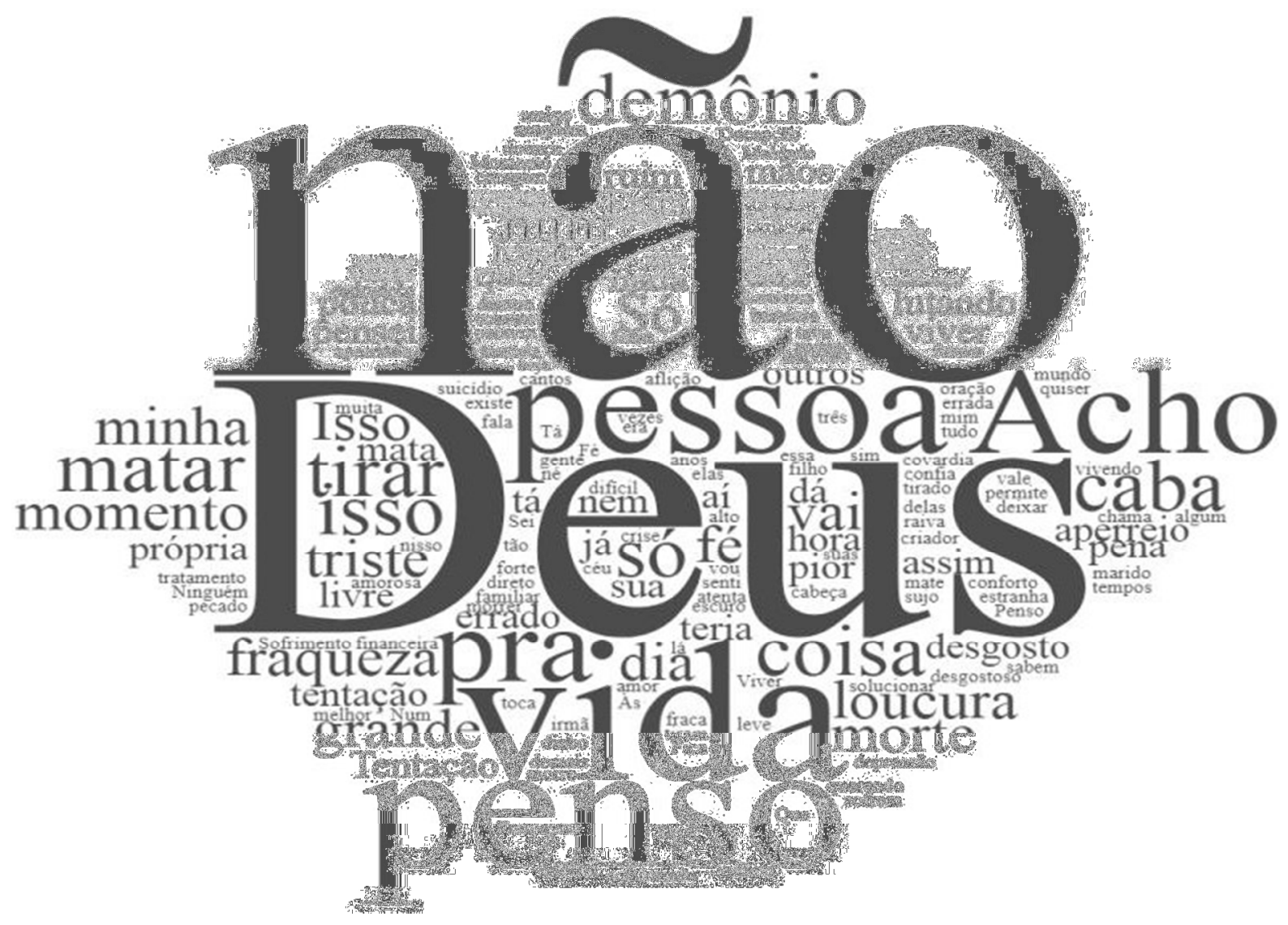

O teor dessas opiniões está fortemente associado às concepções teológicas, políticas e sociais vigentes nos séculos passados, de maneira notável, no qual o suicídio era visto como um ato diabólico e, portanto, de afronta contra Deus. Com a finalidade de reprimir novas ocorrências, o comportamento suicida era severamente punido, através de julgamento e execução pública dos cadáveres e o confisco de bens (MINOIS, 2018).

Ao serem questionados sobre a visão que possuem acerca do suicídio, um número razoável de participantes disseram acreditar que sua ocorrência se dá em resposta ao intenso sofrimento psíquico vivenciado pela pessoa que pratica $o$ ato, como é possível verificar nas seguintes afirmativas: "Acho que deve passar por algum aperreio pra se matar." (P.24); "Eu acho que é pra pessoas que sofrem bastante e não sabem como solucionar." (P.34). "É quandoa pessoa tá num sufoco 
mesmo pra fazer isso aí." (P.39); "Tava muito desgostoso na vida." (P.40); "Eu acho que é uma doença, uma depressão muito forte." (P.49).

A menor frequência com que o suicídio foi associado às explicações de ordem emocional pode ser explicada pelo recente estudo do fenômeno no campo da ciência médica e psicológica (MINOIS, 2018). Apenas nas últimas décadas, assistimos ao surgimento e intensificação de publicações, campanhas e ações governamentais voltadas à prevenção do suicídio no cenário internacional e nacional. Há, portanto, muito ainda a ser descoberto e explicado no campo científico acerca do comportamento suicida.

O suicídio foi significativamente associado a um gesto de loucura e um ato de fraqueza. Esses pensamentos foram ilustrados nas respectivas falas: "Eu acho que é uma loucura grande" (P.8); "... tem hora que o caba perde a cabeça" (P.14); "O caba se matar é a covardia pior que existe" (P.14); "Eu acho que é uma fraqueza muito grande." (P.37).

Alguns entrevistados associam à morte por suicídio uma visão negativa, parecendo diferenciá-la de outros tipos de mortes, assim afirmam: "Acho que é uma morte muito ruim." (P.35); "É muito ruim né?" (P.41); "É uma morte triste." (P.43); "Eu senti muita pena." (P.47).

Numa menor frequência, o suicídio é compreendido como ato voluntário e racional de quem não quer mais viver: "É porque não tava querendo viver mais." (P.40); como escolha errônea que não proporciona uma solução, realmente: "O caba morrer é pior, né!?" (P.7); ou como expressão da falta de confiança em si: "Uma pessoa que não tem confiança... em si (P.19)."

A manifestação das opiniões dos entrevistados demonstra a forma como se comportam de maneira preponderante em relação ao fenômeno. A avaliação preconceituosa sobre osuicídio não contribui no tocante a sua prevenção, já que o olhar negativo lançado sobre os que o vivenciam pode, ao reprimir a sua manifestação, impedir que se busque a efetiva ajuda para lidar com o mesmo. 


\section{CONCLUSÃO}

A significativa ocorrência de ideação suicida, planejamento e tentativa de suicídio na amostra estudada revela que tais fenômenos estão ocorrendo sorrateiramente em parcela da população, ganhando visibilidade apenas quando da manifestação concreta, às vezes fatal, da autoviolência.

É, portanto, imprescindível a adoção de uma postura de vigilância por parte de todos os profissionais que atuam nas políticas públicas de saúde, educação, segurança pública e assistência social. No contexto da saúde, é especificamente no contexto da Rede de Atenção Psicossocial - RAPS que a prevenção deve ocorrer por meio de ações de promoção de saúde mental, da construção do plano terapêutico singular e do cuidadoso fluxo de referências e contra referências entre as equipes da atenção básica, saúde mental e dos serviços de emergência psiquiátrica.

Enfatiza-se aqui a imperiosa necessidade de envolver a comunidade em eventos e debates públicos cujo propósito seja informar a população sobre o comportamento suicida, através de temas como: fatores de risco e de proteção, onde buscar ajuda, formas adequadas de agir mediante o risco. A informação é essencial para que a sociedade civil também possa contribuir com a prevenção de novas ocorrências no cotidiano de suas relações e por meio de ações organizadas. Todos devem ser convocados e atuar harmonicamente com a mesma finalidade.

Em algumas entrevistas houve a detecção de situações de extremo risco de suicídio, fato que suscitou a necessidade do encaminhamento dos participantes em questão às equipes das Unidades Básicas de Saúde e dos Centros de Atenção Psicossocial. Foi também necessário o contato posterior da pesquisadora com familiares de determinado participanteque havia perdido o vínculo com a família, o que permitiu que a situação de vulnerabilidade para o suicídio fosse atenuada.

Por fim, ressalta-se a importância de serem realizadas novas investigações abrangendo uma amostra mais ampla, incluindo também a população residente na zona rural do municípiode Piancó- PB, de maneira que se possa visualizar com mais 
amplitude os diversos fatores que perpassam o comportamento suicida nesse território.

\section{REFERÊNCIAS BIBLIOGRÁFICAS}

ABP. Suicídio: informando para prevenir. Brasília: CFM/ABP, 2014 BERTOLOTE, José. 0 suicídio e sua prevenção. São Paulo: Editora Unesp, 2012 BOTEGA, Neury. Crise Suicida: Avaliação e manejo. Porto Alegre: Artmed, 2015.

CASSORLA, Roosevelt. Suicídio. Fatores inconscientes e aspectos socioculturais: umaintrodução. São Paulo: Blucher, 2017.

CRUZ, Alexandre. Protocolo para Avaliação de Risco de Suicídio. Abordagem pragmática e reflexiva - Uso prático pelas equipes de saúde. Brasília: Coordenação de Saúde Mental.

GONÇALVES, Bruno. Sobre o Desespero. In ANGERAMI, Valdemar (org.) Sobre oSuicídio: A psicoterapia diante da autodestruição. Belo Horizonte: Editora Artesã, 2018.

MINOIS, George. História do Suicídio: a sociedade ocidental diante da morte voluntária. São Paulo: Editora Unesp, 2018.

MS. Agenda de Ações Estratégicas para a Vigilância e Prevenção do Suicídio e Promoção da Saúde no Brasil - 2017 a 2020. Brasília: Ministério da Saúde, 2017.

MS. Departamento de Informática do Sistema Único de Saúde (DATASUS). População residente: Estimativas do IBGE para o TCU - Paraíba. Disponível em: http://tabnet.datasus.gov.br/cgi/tabcgi.exe?ibge/cnv/poptpb.def. Acesso em 28/04/2020.

MS. Departamento de Informática do Sistema Único de Saúde. Óbito por causa externas: Lesões autoprovocadas voluntariamente-Brasil. Disponível em: http://tabnet.datasus.gov.br/cgi/tabcgi.exe?sim/cnv/ext10uf.def. Acesso em 28/04/2020.

OMS. Prevenção do Suicídio: Manual dirigido aos Profissionais da Saúde em Atenção Primária. Genebra: OMS, 2000.

OMS. Prevención del suicidio: un imperativo global. Washington (DC): OMS, 2014.

OMS. Promoción de la salud mental. Conceptos, evidencia emergente, práctica. Informe compendiado. Genebra: OMS, 2004.

TRIGUEIRO, André. Viver é a melhor opção: a prevenção do suicídio no Brasil e no mundo - $3^{\mathrm{a}}$ ed. $1^{\mathrm{a}}$ reimp., rev. São Bernardo do Campo, SP: Correio Fraterno, 2017. 